\title{
An observational study of Alternative Therapies among Paediatric Emergency Department Patients
}

\author{
(Alternative Therapy use among Paediatrics)
}

\section{Investigators:}

\author{
Juen-Li Ding BBioMed MD ${ }^{1}$ \\ David McD Taylor MBBS MD MPH DRCOG FACEM ${ }^{1,2}$ \\ Marina Lee BBioMed MD $\mathrm{MD}^{1,2}$ \\ Olivia Grover Johnson BSc MD ${ }^{1}$ \\ Aadith Ashok BBioMed MD ${ }^{1}$ \\ Meg Griffiths MBBS(Hons) $)^{3,5}$ \\ Leopold Simma MD ${ }^{4}$ \\ Simon S Craig MBBS (Hons) FACEM MHPE ${ }^{3,5,6}$ \\ John A Cheek MBBS FACEM ${ }^{3,4,6}$ \\ Franz E Babl MD MPH FRACP ${ }^{1,4,6}$
}

${ }^{1}$ Department of Medicine, University of Melbourne, Parkville, Victoria, Australia

${ }^{2}$ Emergency Department, Austin Health, Heidelberg, Victoria, Australia

${ }^{3}$ Paediatric Emergency Department, Monash Medical Centre, Emergency Program, Monash Health, Clayton, Victoria, Australia

${ }^{4}$ Royal Children's Hospital, Melbourne, Victoria, Australia

${ }^{5}$ Monash Emergency Research Collaborative, Clinical Sciences at Monash Health, Monash University, Clayton, Victoria, Australia

${ }^{6}$ Murdoch Children's Research Institute, Parkville, Victoria, Australia

\section{Address for Correspondence:}

Professor David Taylor

Emergency Department, Austin Hospital

Studley Road, Heidelberg, Victoria, Australia 3084

Phone (W) +61 394964711

David.Taylor@austin.org.au

\section{Author Contribution}

J-LD, DT, SC, JC and FB designed the study. DT, SC, JC and FB supervised data collection at their sites. J-LD, ML, OGJ, AA, MG and LS collected the data. J-LD and DT analysed the data. All authors helped draft and revise the manuscript and have approved the final draft.

\section{Word count: Text 2,484}

Abstract 241

This is the author manuscript accepted for publication and has undergone full peer review but has not been through the copyediting, typesetting, pagination and proofreading process, which may lead to differences between this version and the Version of Record. Please cite this article as doi: $10.1111 / 1742-6723.12744$

This article is protected by copyright. All rights reserved. 


\begin{abstract}

\section{Objective}

While complementary medicine use among emergency department (ED) paediatric patients is common, the use of Alternative Therapies (AT, physical or spiritual therapies) is unknown. We aimed to determine the 12-month period prevalence and nature of AT use among paediatric patients and parent perceptions of AT use.
\end{abstract}

\title{
Methods
}

We undertook a cross-sectional survey of a convenience sample of parents of paediatric patients in three EDs in metropolitan Melbourne, Australia (January-June, 2015). Parents were invited to complete a validated, anonymous, self-administered questionnaire. The main outcomes were AT use by the patient and parent perceptions of AT.

\section{Results}

806 parents were enrolled. In the previous 12 months, $393(48.8 \%)$ patients had received at least one AT. There were no gender or ethnicity differences between AT users and non-users. AT use was more common among older patients $(\mathrm{p}<0.05)$. Patients with chronic illness tended to use more AT ( $p=0.12) .1091$ courses of 43 different AT had been provided. The most common were massage (16\% of patients), chiropractic therapy $(9.8 \%)$, relaxation $(7.2 \%)$, meditation $(6.2 \%)$ and aromatherapy (6.1\%). ATs were generally used for musculoskeletal problems, health maintenance, stress and anxiety. Parents who arranged the ATs were significantly more likely to report that ATs are safe, prevent and treat illness, assist prescription medicines, and offer a more holistic approach to healthcare $(\mathrm{p}<0.001)$.

This article is protected by copyright. All rights reserved. 


\section{Conclusion}

AT use is common among paediatric ED patients. Parents who arrange AT have differing perceptions of AT usefulness and safety from those who do not.

\section{Key Words:}

complementary medicine, alternative therapy, emergency department, pediatric

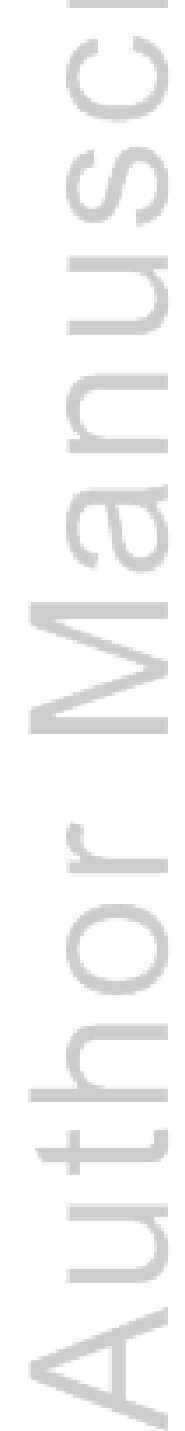

This article is protected by copyright. All rights reserved. 


\section{INTRODUCTION}

Complementary and Alternative Medicine (CAM) has been defined as 'a broad domain of healing resources that encompasses all health systems, modalities, and practices and their accompanying theories and beliefs, other than those intrinsic to the politically dominant health system of a particular society or culture in a given historical period'. ${ }^{1}$ This definition comprises two broad groups: 'Complementary Medicines' which are generally ingested and 'Alternative Therapies' (AT) which are generally physical or spiritual therapies.

Complementary medicines are widely used among paediatric populations although both definitions and period prevalence vary. ${ }^{2-5}$ One recent Australian study reported a $43 \% 12$-month period prevalence of use of complementary medicines for paediatric emergency department (ED) patients. ${ }^{5}$ Although there is no standardized definition for AT, the National Centre for Complementary and Integrative Health defines AT domains as 'whole medical systems' (e.g. naturopathy, homeopathy); 'manipulative and body-based practices' (e.g. chiropractic therapy, massage); 'energy medicine' (e.g. acupuncture) and 'mind body medicine' (e.g. hypnosis, biofeedback). ${ }^{1}$

Unlike complementary medicine use, there is a paucity of literature on AT use. This study aimed to determine the period prevalence and nature of AT use among paediatric ED patients, the patient demographics associated with AT use, and the perceptions of the parents regarding AT use and safety.

This article is protected by copyright. All rights reserved. 


\section{METHODS}

We conducted a cross-sectional survey of the parents of paediatric patients in the EDs of two tertiary and one secondary paediatric care centres in metropolitan Melbourne, Australia (annual paediatric census 17,000-82,000), between January 2015 and June 2015. Ethics committee approval was obtained at each centre.

We enrolled a convenience sample of parents during periods when investigators were available (mostly 09:00-20:00). Parents were suitable for inclusion if their child was aged d 18 years. They were excluded if they were upset, distracted or anxious, or were unable to read and/or complete the study questionnaire.

Participation was voluntary and anonymous. Whether completed or not, the parent was asked to deposit the questionnaire into a sealed box. Completion of the questionnaire was deemed as implied consent.

The questionnaire was the sole source of data. It was based on a questionnaire that was validated and employed in a paediatric complementary medicine study. ${ }^{5}$ Minor revisions ensured its suitability for this AT study. The cover page defined AT and gave examples. Data were collected on the child's demographics and current prescribed medication. Indigenous status was not collected. A list of 40 commonly used AT was presented and the parent was asked to report if any had been administered that day, in the previous week, or the previous 12 months. Details of unlisted ATs administered were also requested. Alternative Therapy 'users' / 'nonusers' were patients who had/ had not had a course of AT in the previous 12 months, 
respectively. Any patient who regularly (daily or intermittently for symptom control) required prescribed medication (e.g. salbutamol) was defined as having a chronic disease.

Data on general perceptions of AT were also collected. Six separate statements were provided e.g. 'Alternative Therapies can prevent children from becoming ill'. For each statement, the parent was asked to record their agreement on a 5-point Likert scale (strongly disagree to strongly agree).

To demonstrate a clinically significant difference between relevant patient subgroups (e.g. males versus females) in AT use of 5\% versus 15\%, at least 160 patients were needed in each subgroup (alpha 0.05, 2-sided, power 0.80). We aimed to enrol at least 800 patients in the expectation that any one of five patient subgroups would have approximately 160 patients.

Data analysis was largely descriptive. The Chi square test was employed to determine variables associated with AT use and to compare item responses. SPSS for Windows statistical software (version 21.0, SPSS Inc., Chicago, Illinois, USA) was used for all analyses (alpha 0.05).

This article is protected by copyright. All rights reserved. 


\section{RESULTS}

Of 917 parents invited to participate, $806(87.9 \%)$ were enrolled. The child's mother was the respondent in most cases $(600,74.8 \%)$. The mean (SD) patient age was 6.7 (5.1) years, 427 (53.3\%) were male, 448 (57.4\%) had Australian/New Zealand/British ethnicity, and $184(22.8 \%)$ had a chronic disease (Table 1).

On the day of presentation, in the previous week, and in the previous 12 months, 45 $(5.6 \%, 95 \%$ CI $4.1,7.5), 150(18.6 \%, 95 \%$ CI 16.0, 21.5) and $393(48.8 \%, 95 \%$ CI $45.3,52.3$ ) patients had received a course of AT, respectively. Older children were significantly more likely to be AT users $(\mathrm{p}=0.03)$. There was no gender or ethnic group difference between AT users and non-users. Patients with chronic illness tended to use more AT $(p=0.12)$ (Table 1$)$.

A total of 1091 courses of AT had been provided in the previous 12 months. These comprised 43 different AT, including all 40 listed in the questionnaire and 3 not listed (kinesiology 9 courses, salt therapy 3, myotherapy 2). The most commonly AT used were massage, chiropractic therapy, relaxation techniques, meditation and aromatherapy (Table 2). One child had a total of 18 different AT within the previous year.

Two hundred and thirty three parents (60\% of AT users) reported details of the 350 AT courses administered within the previous 12 months (Table 2). AT were used most commonly for musculoskeletal soreness, stiffness, pain and injury (massage,

This article is protected by copyright. All rights reserved. 
chiropractic therapy, osteopathic manipulation), general health maintenance and wellbeing (chiropractic therapy, meditation, yoga, osteopathic manipulation, naturopathy, Chinese traditional medicine), upper respiratory tract infections including colds, flu and cough (aromatherapy, naturopathy, homeopathy, Chinese traditional medicine) stress relief and relaxation (relaxation techniques, meditation, aromatherapy, yoga, arts therapy) as well as physical alignment and adjustment (chiropractic therapy, osteopathic manipulation). Specific diseases for which AT were used included gastrointestinal disease (Coeliac and Crohn's disease), atopic disease (eczema, asthma and allergic rhinitis) as well as cerebral palsy, autism, attention deficit and hyperactivity disorders.

Table 3 describes AT use as a function of age. Overall, mind-body medicine courses were used most often. However, mind-body medicine was uncommon in the 0-2 year age group. Manipulative and body based practices were also common, including within the 0-2 year age group. AT use (AT courses/child) for children aged 12-18 years was highest except for whole medical systems.

Only nine cases of adverse effects (AEs) associated with AT use were reported: yoga (2 cases), play therapy (1), osteopathic manipulation (1), massage (1), craniosacral manipulation (1), hypnotherapy (1) chiropractic therapy (1) and aromatherapy (1). Details of the AEs were not reported except for one child who experienced increased anxiety following hypnotherapy.

This article is protected by copyright. All rights reserved. 
The use of AT had not been recommended by a third party in 121 cases. In other cases, the AT had been recommended by a friend/relative (81 cases), a doctor (42), an alternative therapist (33) and others.

In 130 cases, the AT use was not disclosed to other individuals. However, the family doctor was aware of the AT use in 122 cases. Of those who had used an AT within the previous week, 21(20\%) parents had informed the ED doctor. For those who had not informed the ED doctor, reasons for this were that the doctor did not ask (40 cases), AT were harmless (22), the doctor did not need to know (8) and the doctor would disapprove (1).

Overall, $494(61.4 \%, 95 \%$ CI $57.9,64.7)$ parents agreed/strongly agreed that AT can be used to assist prescription medicines, $409(50.8 \%, 95 \%$ CI $47.3,54.3)$ that AT could treat illness, $383(47.7 \%, 95 \%$ CI $44.2,51.2)$ that AT are safe, $293(36.4 \%, 95 \%$ CI $33.0,39.8)$ that AT could prevent illness and $256(32.0 \%, 95 \%$ CI $28.8,35.4)$ that AT offered a more holistic approach to health (Table 4). For each of these items, the perceptions of parents of AT users differed significantly from parents of non-users $(\mathrm{p}<0.001)$. In addition, $87(10.8 \%, 95 \%$ CI $8.8,13.2)$ parents agreed/strongly agreed that AT were more effective than prescription medicines. For this item, the perceptions of parents of AT users and non-users did not differ.

This article is protected by copyright. All rights reserved. 


\section{DISCUSSION}

The use of AT is common and a wide range of AT are used. Indications of AT prevalence can be gleaned from CAM studies which report 12 month period prevalence of 'non-medicinal' CAM or 'CAM practices' that range between $12 \%$ to $23 \%{ }^{2,3,6}$ However, our 12 month period prevalence is considerably in excess of these earlier reports.

Alternative therapy use is likely to vary with the study setting and sample population. As patients with chronic illness tended to use more AT, it is possible that AT prevalence may be higher in other hospital settings. This is the case for CAM, with high CAM prevalence reported in paediatric oncology $(6 \%-91 \%)^{7}$, epilepsy $(22.6 \%$ $95 \%)^{8-10}$ and cerebral palsy $(56 \%)^{11}$.

The differences between our AT prevalence and those of other reports are difficult to explain. Definitions of AT and CAM are often confused or used interchangeably. Differing study methodologies is also likely to affect the results. Although most reports have included AT as a subgroup of CAM, we defined and targeted AT specifically. Finally, it is possible that AT use has increased in recent years.

The most common ATs were massage, chiropractic therapy, relaxation techniques, meditation and aromatherapy. These findings are consistent with other reports. Adam et al. ${ }^{6}$ reported that the more common 'CAM practices' or AT included massage, faith healing, chiropractic therapy, aromatherapy and relaxation. It has been reported that children account for $14 \%$ of visits to chiropractors, a proportion very similar to

This article is protected by copyright. All rights reserved. 
ours. ${ }^{12,13}$ Dieter et al. ${ }^{14}$ reported that massage therapy is used routinely in neonatal Intensive Care Units in preterm infants. Other common AT, including naturopathy, osteopathy, homeopathy and acupuncture, have been reported previously. ${ }^{3,4,15,16}$ Homeopathy is used in $2-10 \%$ of children to treat simple respiratory conditions as well as ear, nose and throat conditions. ${ }^{13,17}$ Zuzak et al. ${ }^{18}$ reported that $45 \%$ of Swiss paediatric ED patients used homeopathy.

The main reasons for AT use included musculoskeletal problems, health maintenance, and relief of stress and anxiety. Similar reasons for CAM use have been reported including musculoskeletal, psychological and infectious disease ${ }^{4}$, physical stabilization, relaxation ${ }^{16}$, general health maintenance, upper respiratory symptoms and eczema ${ }^{3}$, and gastrointestinal disease ${ }^{19}$. However, as with AT and CAM use prevalence, the reasons for AT and CAM use cannot be compared directly.

In this study, older children were more likely to be an AT user. This is similar to the findings of a number of CAM studies. Adams et al. ${ }^{6}$ reported that, for every 5 year increase in age, the odds of CAM use increased by 1.4. Lim et al. ${ }^{3}$ and Taylor et al. ${ }^{5}$ found CAM use to be higher among those above 2 years of age. The finding that ethnicity and gender are not associated with AT use is consistent with those of CAM studies. $^{2,3,16}$

Patients with a chronic illness tended to have greater AT use. To date, no reports have specifically examined this association and the findings of CAM studies have been mixed. Gottschling et al. ${ }^{16}$ reported comparable usage between healthy children and those with chronic conditions. While Hughes and Wingard ${ }^{20}$ associated CAM use 
with children in good health, Adams et al. ${ }^{6}$ associated CAM use with poor health. Taylor et al..$^{5}$ reported that CAM use was significantly greater among patients who had a chronic disease.

Given the popularity of AT and their potential cost, there is a need for better evidence of their efficacy and safety. Hunt et al. ${ }^{21}$ revealed a benefit for acupuncture in postoperative nausea and vomiting, hypnosis in procedure related pain, and massage therapy for the growth and development of preterm infants and sleep. However, the majority of studies they examined showed weak or no evidence of AT efficacy and many were limited by their methodology. Posadzki et al. ${ }^{22}$ reported that osteopathic manipulation had no effect on a number of conditions including asthma and cerebral palsy. Although some trials had shown AT to be effective in infantile colic and postural asymmetry, these trials also had poor methodology. Despite this lack of evidence, osteopathic manipulation was, in fact, used for cerebral palsy and postural asymmetry in our study.

Adverse events have been reported following AT use. Adams et al. ${ }^{6}$ reported 80 AEs associated with CAM, including a number associated with AT. Although our study was not designed to assess the safety of ATs, adverse effects were associated with a range of AT. However, these AEs were self-assessed and not further specified.

Parent knowledge of AT efficacy and safety was generally poor. Many parents viewed AT as a suitable method to both prevent and treat illness, and viewed AT as safe. There are similar reports of perceptions of CAM. Adams et al. ${ }^{6}$ reported that $76.2 \%$ of parents believed that AT were healthy, a finding consistent with other 
studies. ${ }^{15,16}$ It has been reported that $75 \%$ and $61 \%$ of parents of children with epilepsy ${ }^{10}$ and otolaryngological conditions ${ }^{23}$, respectively, believe that CAM are effective. Parental perceptions of safety are not as widely known, although one study showed that $75 \%$ of CAM users believed that CAM induced no AEs. ${ }^{4}$ In our study, the clear differences in perceptions of AT between parents of AT users and non-users were expected and consistent with one CAM study. ${ }^{5}$ Hurvitz et al. ${ }^{11}$ also reported greater AT/CAM use and positive perceptions when the parents used these therapies themselves.

The high prevalence of AT use and positive AT perceptions have implications for medical practice. The use of AT on the day of presentation and in the preceding week was substantial. Concurrent treatment regimens may impact upon efficacy, safety and management compliance. As AT use is infrequently disclosed to the ED doctor, this information should be deliberately sought. This may inform management decisions and patient education. Patient education needs to be informed and nonjudgmental. ${ }^{24}$ Accordingly, suitable reference resources should be available and accessed.

This study has a number of limitations. Non-participation and the exclusion of nonEnglish speakers may have introduced selection bias. Participation may have been affected by parental perceptions of AT, including a belief that the doctor may disapprove of their use. With the self-administration of the questionnaire, the characteristics of non-respondents are not known. However, the response rate was high and substantial selection bias is unlikely. 
Specific details of individual AT used were often not provided, with $60 \%$ of AT users completing this section. Hence, details of the reasons for the AT use and AEs are incomplete. Recall bias may have affected the results. There may have been bias towards the 40 AT listed in the questionnaire with under-reporting of those not listed.

The participating EDs are likely to have paediatric populations representative of children in multi-cultural Melbourne. However, there may have been an overrepresentation of children with chronic disease as some of the EDs were within major paediatric centres.

This article is protected by copyright. All rights reserved. 


\section{CONCLUSION}

Despite limited evidence of efficacy, the use of AT is common amongst paediatric ED patients. The most commonly used AT include massage, chiropractic therapy, relaxation techniques, meditation and aromatherapy. Alternative therapy use is associated with older age but no other demographic characteristics. The perceptions of the parents of AT users and non-users differed significantly with the parents of users being significantly more favorable to AT use. As AT use is rarely reported to ED physicians, they should seek this information in order to provide the most informed management strategies.

This article is protected by copyright. All rights reserved. 


\section{Acknowledgements}

nil

\section{Competing Interests}

none declared

\section{Funding}

nil

C
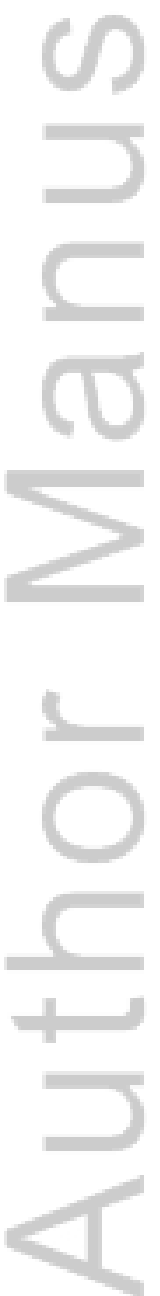

This article is protected by copyright. All rights reserved. 


\section{REFERENCES}

1. Wieland LS, Manheimer E, Berman BM. Development and classification of an operational definition of complementary and alternative medicine for the Cochrane Collaboration. Alt Therap Health Med 2011; 17: 50-59

2. Crawford NW, Cincotta DR, Lim A, Powell CVE. A cross-sectional survey of complementary and alternative medicine use by children and adolescents attending the University Hospital of Wales. BMC Comp Alt Med 2006; 6 (16)

3. Lim A, Cranswick N, Skull S, South M. Survey of complementary and alternative medicine use at a tertiary children's hospital. J Paed Child Health 2005; 41: 424-427

4. Jean D, Cyr C. Use of complementary and alternative medicine in a general pediatric clinic. Pediatrics 2007; 120: e138-141

5. Taylor DMcD, Dhir R, Craig SS, Lammers T, Gardiner K, Hunter K, Joffe P, Krieser D, Babl FE. Complementary and alternative medicine use among paediatric emergency department patients. J Paed Child Health 2015; 51: 895-900

6. Adams D, Dagenais S, Clifford T, Baydala L, King WJ, Hervas-Malo M, et al. Complementary and alternative medicine use by pediatric specialty outpatients.

Pediatrics 2013; 131: 225-232

7. Bishop FL, Prescott P, Chan YK, Saville J, Von Elm E, Lewith GT. Prevalence of complementary medicine use in pediatric cancer: A systematic review. Pediatrics 2010; 125: 768-776

8. Goker Z, Serin HM, Hesapcioglu S, Cakir M, Sonmez FM. Complementary and alternative medicine use in Turkish children with epilepsy. Complement Ther Med 2012; 20: 441-446

This article is protected by copyright. All rights reserved. 
9. Ekici B, Tatli B, Abali S, Aydinli N, Ozmen M. Application of complementary and alternative medicine in epileptic children at a tertiary pediatric neurology center in Turkey. Eur J Integ Med 2012; 4: e71-e75

10. Doering JH, Reuner G, Kadish NE, Pietz J, Schubert-Bast S. Pattern and predictors of complementary and alternative medicine (CAM) use among pediatric patients with epilepsy. Epilepsy Behav 2013; 29: 41-46

11. Hurvitz EA, Leonard C, Ayyangar R, Simson Nelson V. Complementary and alternative medicine use in families of children with cerebral palsy. Dev Med Child Neurol 2003; 45: 364-370

12. Birdee GS, Phillips RS, Davis RB, Gardiner P. Factors associated with pediatric use of complementary and alternative medicine. Pediatrics 2010; 125: 249-256

13. Sawni-Sikand A, Schubiner H, Thomas RL. Use of complementary/alternative therapies among children in primary care pediatrics. Ambul Pediatrics 2002; 2: 99103 14. Dieter JNI, Field T, Hernandez-Reif M, Emory EK, Redzepi M. Stable preterm infants gain more weight and sleep less after five days of massage therapy. $J$ Pediatr Psych 2003; 28: 403-411

15. Low E, Murray DM, O'Mahony O, J OBH. Complementary and alternative medicine use in Irish paediatric patients. Irish J Med Sci 2008; 177: 147-150 16. Gottschling S, Gronwald B, Schmitt S, Schmitt C, Langler A, Leidig E, et al. Use of complementary and alternative medicine in healthy children and children with chronic medical conditions in Germany. Complement Ther Med 2013; 21 Suppl 1: S61-69

17. Pitetti R, Singh S, Hornyak D, Garcia SE, Herr S. Complementary and alternative medicine use in children. Pediatr Emerg Care 2001; 17: 165-169

This article is protected by copyright. All rights reserved. 
18. Zuzak TR, Zuzak-Siegrist I, Rist L, Staubli G, Simoes-Wust AP. Medicinal Systems of Complementary and Alternative Medicine: A Cross-Sectional Survey at a Pediatric Emergency Department. J Altern Complement Med 2010; 16: 473-479 19. Dolceamore TR, Altomare F, Zurlo F, Miniero R. Use of alternativecomplementary-medicine (CAM) in Calabrian children. Ital J Pediatr 2012; 38: 1-6 20. Hughes SC, Wingard DL. Children's Visits to Providers of Complementary and Alternative Medicine in San Diego. Ambul Pediatr 2006; 6: 293-296

21. Hunt K, Ernst E. The evidence-base for complementary medicine in children: a critical overview of systematic reviews. Arch Dis Childhood 2011; 96: 769-776 22. Posadzki P, Lee MS, Ernst E. Osteopathic manipulative treatment for pediatric conditions: a systematic review. Pediatrics 2013; 132: 140-152

23. Shakeel M, Little SA, Bruce J, Ah-See KW. Use of complementary and alternative medicine in pediatric otolaryngology patients attending a tertiary hospital in the UK. Int J Pediatr Otorhinolaryngol 2007; 71: 1725-1730

24. Kemper KJ, Sunita Vohra S, Walls R, the Task Force on Complementary and Alternative Medicine, the Provisional Section on Complementary, Holistic, and Integrative Medicine. The Use of Complementary and Alternative Medicine in Pediatrics. Pediatrics 2008; 122: 1374-1386

This article is protected by copyright. All rights reserved. 
Table 1. Patient demographics and medical history $(n=806)$

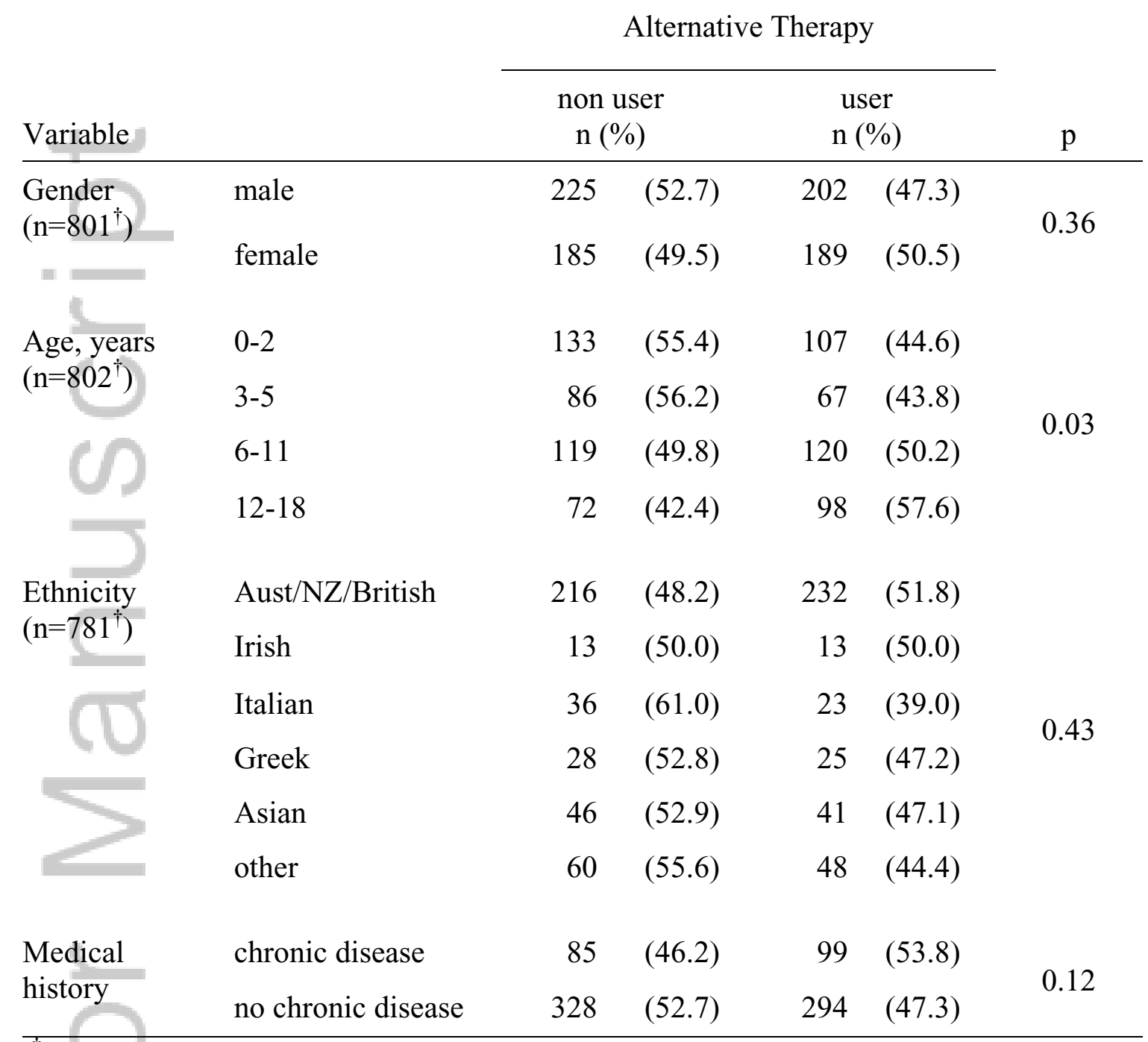

${ }^{\dagger}$ Data incomplete for some cases

Aust/NZ/British, Australian/New Zealander/British

This article is protected by copyright. All rights reserved. 
Table 2. The most common Alternative Therapies administered within the previous 12 months and the common reasons for administration

\begin{tabular}{|c|c|c|c|c|}
\hline $\begin{array}{l}\text { Alternative } \\
\text { Therapy }\end{array}$ & $\mathrm{n}$ & $\begin{array}{l}\% \text { of all } \\
\text { courses }\end{array}$ & $\begin{array}{l}\% \text { of all } \\
\text { patients }\end{array}$ & Reason for administration ( $\%$ of all reasons) \\
\hline Massage & 178 & 16.3 & 22.1 & $\begin{array}{l}\text { musculoskeletal issues (40), relaxation (32.7), } \\
\text { bowel issues (9.1) }\end{array}$ \\
\hline $\begin{array}{l}\text { Chiropract } \\
\text { therapy }\end{array}$ & 107 & 9.8 & 13.3 & $\begin{array}{l}\text { musculoskeletal issues (35.4), physical } \\
\text { alignment/adjustment (18.5), health } \\
\text { maintenance/wellbeing (10.8), sleep (6.2) }\end{array}$ \\
\hline Relaxatic & 79 & 7.2 & 9.8 & Stress/anxiety (46), sleep (31) \\
\hline Meditatic & 68 & 6.2 & 8.4 & $\begin{array}{l}\text { relieve stress, promote relaxation }(53) \text {, health } \\
\text { maintenance/wellbeing }(23.5) \text {, school routine } \\
(11.8)\end{array}$ \\
\hline Aromatherapy & 67 & 6.1 & 8.3 & $\begin{array}{l}\text { relieve stress, promote relaxation (26), sleep (22), } \\
\text { upper respiratory tract infection (22) }\end{array}$ \\
\hline Yoga & 56 & 5.1 & 6.9 & $\begin{array}{l}\text { relaxation (25), health maintenance/wellbeing } \\
(16.7)\end{array}$ \\
\hline Arts Therapy & 55 & 5.0 & 6.8 & anxiety (29) \\
\hline $\begin{array}{l}\text { Osteopathic } \\
\text { manipulation }\end{array}$ & 55 & 5.0 & 6.8 & $\begin{array}{l}\text { musculoskeletal issues (53.3), physical alignment } \\
\text { /adjustment (16.7), health maintenance/wellbeing } \\
\text { (6.7) }\end{array}$ \\
\hline Naturopathy & 53 & 4.9 & 6.6 & $\begin{array}{l}\text { bowel issues }(21) \text {, atopic disease }(21) \text {, upper } \\
\text { respiratory tract infection }(14) \text {, health } \\
\text { maintenance/wellbeing }(10.7)\end{array}$ \\
\hline Homeopathy & 50 & 4.6 & 6.2 & upper respiratory tract infection (38.9) \\
\hline Play Therapy & 48 & 4.4 & 6.0 & $\begin{array}{l}\text { distraction technique, calming technique, } \\
\text { attention deficit hyperactivity disorder, autism }\end{array}$ \\
\hline $\begin{array}{l}\text { Chinese } \\
\text { Traditional } \\
\text { Medicine }\end{array}$ & 35 & 3.2 & 4.3 & $\begin{array}{l}\text { upper respiratory tract infection ( } 30.8) \text {, health } \\
\text { maintenance/wellbeing }(23) \text {, atopic disease } \\
\text { (15.4), constipation (15.4) }\end{array}$ \\
\hline
\end{tabular}

Less common AT: Acupressure (17 courses), Acupuncture (17), Hydrotherapy (17), Spiritual healing (17) Therapeutic touch (16), Imagery (16), Craniosacral manipulation (14), Reiki therapy (13), Biofeedback (10), Ayurvedic traditional medicine (10), Light therapy (9), Kinesiology (9), Reflexology (8), Distant healing (7), Hypnosis (7), Electrical stimulation therapy (6), Traditional healers and healing(6), Moxibustion (5), Balneotherapy (5), Hyperbaric oxygenation (4), Ultrasonic therapy (4), Salt therapy (3), Magnetic field therapy (3), Alexander technique (3), Chelation therapy (3), Color therapy (2), Snoezelen (2), Myotherapy (2), Electromagnetic therapy (2), Prolotherapy (2), Ozone therapy (1). 
Table 3. Alternative Therapy administration as a function of age

\begin{tabular}{|c|c|c|c|c|c|}
\hline age, years (n) & $\begin{array}{c}\text { Whole } \\
\text { medical } \\
\text { systems }^{\dagger} \\
\text { n (n/child) }\end{array}$ & $\begin{array}{c}\text { Energy } \\
\text { medicine }\end{array}$ & $\begin{array}{c}\text { Manipulative } \\
\text { body based } \\
\text { practices }^{\S} \\
\text { n (n/child) }\end{array}$ & $\begin{array}{l}\text { Mind-body } \\
\text { medicine } \\
\text { n (n/child) }\end{array}$ & $\begin{array}{c}\text { other }^{¥} \\
\text { n (n/child) }\end{array}$ \\
\hline $0-2(240)$ & $36(0.15)$ & $25(0.1)$ & $100(0.42)$ & $46(0.19)$ & $6(0.025)$ \\
\hline $3-5 \quad(153)$ & $29(0.19)$ & $12(0.08)$ & $51(0.33)$ & $85(0.56)$ & $4(0.03)$ \\
\hline $6-11 \quad(239)$ & $57(0.24)$ & $45(0.19)$ & $108(0.45)$ & $153(0.64)$ & $19(0.08)$ \\
\hline $12-18 \quad(170)$ & $25(0.15)$ & $49(0.29)$ & $107(0.63)$ & $126(0.74)$ & $6(0.04)$ \\
\hline
\end{tabular}

${ }^{\dagger}$ Ayurvedic medicine, Chinese Traditional Medicine, Homeopathy, Naturopathy

$\$$ Acupressure, Acupuncture, Distant Healing, Electrical stimulation therapy, Electromagnetic field therapy, Light therapy, Magnetic field therapy, Moxibustion, Reiki Therapy, Spiritual Healing, Therapeutic Touch, Traditional healers, Ultrasonic Therapy, Kinesiology

$\S$ Alexander technique, Chiropractic therapy, Craniosacral manipulation, Massage, Osteopathic manipulation, Reflexology, Myotherapy

"Aromatherapy, Arts therapy, Biofeedback therapy, Color therapy, Hypnosis, Imagery, Meditation, Play therapy, Relaxation, Snoezelen, Yoga

${ }^{¥}$ Balneotherapy, Chelation therapy, Hydrotherapy, Hyperbaric oxygenation, Ozone therapy, Prolotherapy, Salt therapy

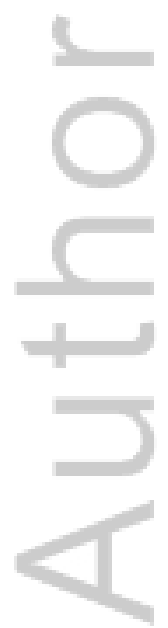


Table 4. Parent perceptions of Alternative Therapies (AT)

\begin{tabular}{|c|c|c|c|c|c|c|}
\hline \multirow[b]{2}{*}{ statement } & \multicolumn{5}{|c|}{ responses to statement, $\mathrm{n}(\%)$} & \multirow[b]{2}{*}{$\mathrm{p}$} \\
\hline & $\begin{array}{l}\text { strongly } \\
\text { disagree }\end{array}$ & disagree & neither & agree & $\begin{array}{c}\text { strongly } \\
\text { agree }\end{array}$ & \\
\hline \multicolumn{7}{|c|}{ AT to assist prescription medicines $\left(n=805^{\dagger}\right)$} \\
\hline non user & $17(4.1)$ & $39(9.5)$ & $145(35.2)$ & $185(44.9)$ & $26(6.3)$ & \multirow{2}{*}{$<0.001$} \\
\hline user & $6(1.5)$ & $25(6.4)$ & $79(20.1)$ & $233(59.3)$ & $50(12.7)$ & \\
\hline \multicolumn{7}{|c|}{ AT can treat illness $\left(n=805^{\dagger}\right)$} \\
\hline non user & $18(4.4)$ & $61(14.8)$ & $172(41.6)$ & $143(34.6)$ & $19(4.6)$ & \multirow{2}{*}{$<0.001$} \\
\hline user & $8(2.0)$ & $36(9.2)$ & $101(25.8)$ & $204(52.0)$ & $43(11.0)$ & \\
\hline \multicolumn{7}{|c|}{ AT are safe $\left(n=803^{\dagger}\right)$} \\
\hline non user & $12(2.9)$ & $48(11.6)$ & $202(48.9)$ & $135(32.7)$ & $16(3.9)$ & \multirow{2}{*}{$<0.001$} \\
\hline user & $3(0.8)$ & $27(6.9)$ & $128(32.8)$ & $181(46.4)$ & $51(13.1)$ & \\
\hline \multicolumn{7}{|c|}{ AT can prevent illness $\left(n=806^{\dagger}\right)$} \\
\hline non user & $20(4.8)$ & $67(16.2)$ & $217(52.5)$ & $92(22.3)$ & $17(4.1)$ & \multirow{2}{*}{$<0.001$} \\
\hline user & $11(2.8)$ & $36(9.2)$ & $162(41.2)$ & $141(35.9)$ & $43(10.9)$ & \\
\hline \multicolumn{7}{|c|}{ AT provide a holistic and wholesome approach compared to conventional medicine $\left(n=800^{\dagger}\right)$} \\
\hline non user & $33(8.0)$ & $79(19.3)$ & $192(46.8)$ & $94(22.9)$ & $12(2.9)$ & \multirow{2}{*}{$<0.001$} \\
\hline user & $11(2.8)$ & $58(14.9)$ & $171(43.8)$ & $107(27.4)$ & $43(11.0)$ & \\
\hline \multicolumn{7}{|c|}{ AT is more effective than prescription medicines $\left(n=804^{\dagger}\right)$} \\
\hline non user & $55(13.3)$ & $154(37.4)$ & $165(40.0)$ & $30(3.7)$ & $8(1.9)$ & \multirow{2}{*}{0.39} \\
\hline user & $40(10.2)$ & $142(36.2)$ & $161(41.1)$ & $41(5.1)$ & $8(2.0)$ & \\
\hline
\end{tabular}

${ }^{\dagger}$ data incomplete for some cases

This article is protected by copyright. All rights reserved. 


\section{University Library}

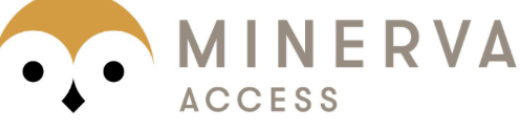

A gateway to Melbourne's research publications

Minerva Access is the Institutional Repository of The University of Melbourne

Author/s:

Ding, J-L;Taylor, DM;Lee, M;Johnson, OG;Ashok, A;Griffiths, M;Simma, L;Craig, SS;Cheek, JA;Babl, FE

Title:

Observational study of alternative therapies among paediatric emergency department patients

Date:

2017-04-01

Citation:

Ding, J. -L., Taylor, D. M., Lee, M., Johnson, O. G., Ashok, A., Griffiths, M., Simma, L., Craig, S. S., Cheek, J. A. \& Babl, F. E. (2017). Observational study of alternative therapies among paediatric emergency department patients. EMERGENCY MEDICINE AUSTRALASIA, 29 (2), pp.136-142. https://doi.org/10.1111/1742-6723.12744.

Persistent Link:

http://hdl.handle.net/11343/292496 